\title{
THE EFFECT OF TEMPERATURE AND RELATIVE HUMIDITY UPON THE OLFACTORY RESPONSES OF BLOWFLIES
}

\author{
By CyrIL E. ABBotT \\ Morgan Park, Ill.
}

\section{Introduction}

It appears that almost no effort has been made to determine the possible conditioning of insect olfaction by other external factors. This may be due to the fact that studies in the relation of these factors to insect metabolism are comparatively recent. In 1917 Headlee discovered that atmospheric moisture, through its relation to the water optimum of the insect body, directly affects development. In the same year Hamilton found that above $20^{\circ} \mathrm{C}$ soil insects are especially sensitive to evaporation. Shelford (1913) observed that insects resisted drying more effectively that most other animals. Beattie (1928) has made some interesting experiments with Calliphora erythrocephala. She finds that a relative humidity of 70 is optimum for the species, and that saturated or dry air lowers the thermal death point. Miller (1930) finds that at $37.5^{\circ} \mathrm{C}$ the percentage of surviving adult Mexican bean beetles, irrespective of humidity, is high. At $42.5^{\circ} \mathrm{C}$ the percentage is low at all humidities, while at temperatures between the extremes, the greatest percent of survival is at a relative humidity of 73. Marchand (1920) observes that Blatta, Chionea and various species of mosquitoes orient to heat. According to Herter (1923) Formica rufa distinguishes temperature changes as low as $1 / 4^{\circ} \mathrm{C}$. Miller and Gan were able to make Cremastogaster lineolata orient to radiant heat. Lodge (1918) finds that Musca domestica has its feeding reactions affected by changes in temperature and humidity. 
The following study was suggested by Kennedy's (1927) statement that the olfactory powers of certain Hymenoptera appear to vary with relative humidity. Under normal conditions, adults of Lucilia sericata Meig. react to ethyl butyrate by an extension of the proboscis and regurgitation of fluid (Fig. 1). This is a definite feeding response to olfactory stimulation. The problem was to determine to what extent this response is dependent upon temperature and relative humidity.

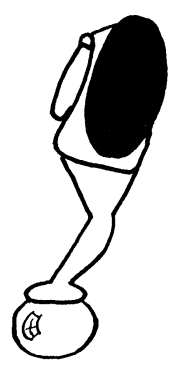

Fig. 1. Extension of proboscis and regurgitation by Lucilia sericata.

\section{Materials and Methods}

Adult flies were kept in small cages and fed a solution of cane sugar and what juices they could obtain from hog's liver. The latter was replaced every alternate day, and any eggs removed to flower pots about two-thirds full of sand. These containers were covered with muslin. The maggots pupated in the sand and as soon as adult flies began to emerge in a given container, the latter was transferred to one of the cages.

Flies were tested individually and discarded after each test. The insect was placed in a chamber consisting of a test tube fitted with a rubber stopper having two inlet tubes. During the test, this tube was kept in a constant temperature bath composed of an aquarium fitted with two Lolag heaters, a thermostat, a stirring device, and two U-tubes which served to equalize the temperature of the air drawn into the fly chamber. One of these tubes was connected with the "check" apparatus; the other with the "test" apparatus. When properly adjusted, the temperature of the 
tank never varied more than $1 / 5^{\circ} \mathrm{C}$. Each of the units used for the control of humidity consisted of two bottles arranged so that air was drawn through solutions they contained; in addition, the "test" set had a vessel containing ethyl butyrate shunted between these bottles and the Utube. This vessel was held at a constant temperature of $30^{\circ} \mathrm{C}$. in all tests.

Relative humidity was controlled by chemicals. A concentrated solution of a given compound gives the air with which it comes in contact a definite relative humidity. Four were used:

$\begin{array}{cc}\text { Chemical } & \text { Relative humidity } \\ \mathrm{H}_{2} \mathrm{O} & 98-100 \\ \mathrm{NaCl} & 73 \\ \mathrm{NaOH} & 30 \\ \mathrm{~N}_{2} \mathrm{SO}_{4} & 0-4\end{array}$

The general method was to change the humidity, the temperature being constant. The tests at the four humidities were then repeated for another temperature. Three temperatures were used: $20^{\circ} \mathrm{C} ., 30^{\circ} \mathrm{C}$, and $40^{\circ} \mathrm{C}$.

Flies were collected in the afternoon and were kept without food for five hours. They had free access to water. Sixty-four flies were used in each test. The method of procedure was as follows: a fly was secured on the end of a galvanized iron wire by wrapping its wings and the end of the wire with adhesive tape. The opposite end of the wire was fixed in the lower surface of the rubber stopper of the test chamber. This last, containing the stopper with the attached fly and tubes was placed in the constant temperature bath for one minute. One inlet tube was attached, by means of a rubber tube, to the "check" apparatus. The other inlet tube was similarly attached to a water-pump. The fly was observed for thirty seconds. If it did not respond (which was generally the case) the tube attached to the "check" apparatus was transferred to the "test" apparatus. Again the fly was observed for thirty seconds. If it extended the proboscis within this time, it was considered "positive." Sexes were used in about equal numbers. Percentage of response was based upon the number 
of insects giving a positive reaction at a definite temperature and humidity.

\section{Results}

The results of the foregoing tests are embodied in the following graph (Fig. 2). Neither at $20^{\circ}$ C. nor at $40^{\circ}$ C. was the percentage of response very high. The highest $(57 \%)$ took place at $20^{\circ} \mathrm{C}$. in a saturated atmosphere. At $30^{\circ} \mathrm{C}$. there was a rise in percentage of response almost directly proportional to the increase in humidity, until the latter reached $73 \%$, after which it fell slightly. At $30^{\circ}$ C. and a

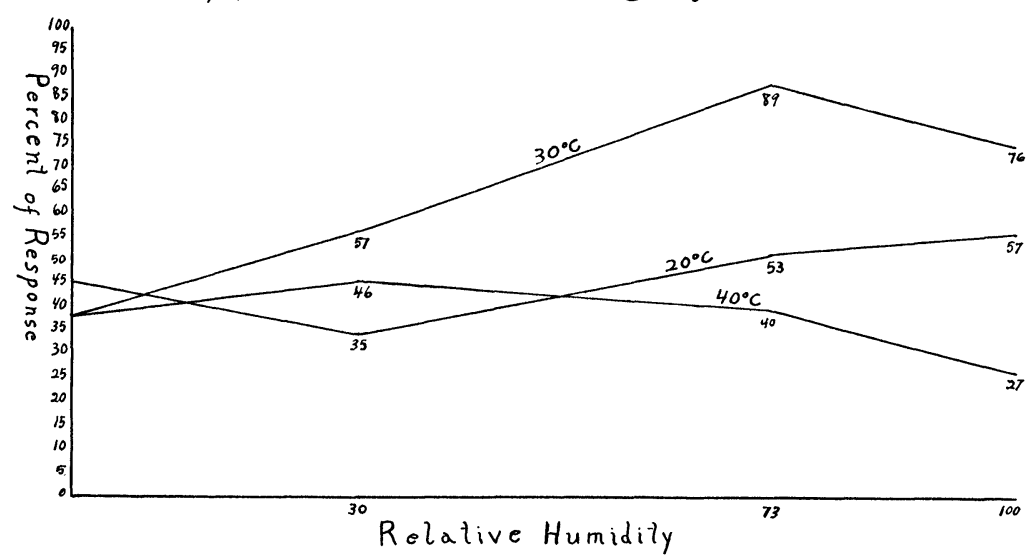

Fig. 2. Olfactory responses of blow-flies.

humidity of $73 \%$ the percent of response was 89 ; at a humidity of $100 \%$ it was 76 . There was no indication of sex differences in these responses. The fact that there were practically no responses to the "check" indicates that it was really the vapor of ethyl butyrate and not air currents that brought about the responses.

\section{General Conclusions}

Several months of breeding and general observations indicate that the most favorable temperature for the metabolism of $L$. sericata is about $30^{\circ} \mathrm{C}$. In the light of this fact, the discrepancies between the behavior of flies tested at that temperature and those tested at other temperature ranges can be easily understood. Apparently it is only at 
the temperature of metabolic optimum that humidity has much effect on their olfactory responses. At that temperature, the optimum for humidity is $73 \%$.

It is a pleasure to thank Dr. C. H. Kennedy, Dr. W. M. Barrows, and Dr. D. F. Miller for many suggestions, materials, and aid in carrying this problem to a successful conclusion.

\section{LITERATURE CITED}

Beattie, M. F. V. 1928. Bul. Ent. Research, 18, 397-403 Hamilton, C. C. 1917. Biol. Bul., 32, 159-177

Headlee, T. J. 1917. Jour. Econ. Ent., 10, 31-38

Herter, K. 1923. Biol. Zentbl., 43, 282-285

Kennedy, C. H. 1927. Ann. Ent. Soc. Amer., 20, 87-106

Lodge, Olive C. 1918. Bul. Ent. Research, 9, 141-151

Marchand, W. 1920. Ent. News, 31, 159-161

Miller, D. F. and M. Gan 1926. Jour. Compar. Psychol.

Miller, D. F. 1930. Jour. Econ. Ent., 23, 945-955

Shelford, V. E. 1913. Biol. Bul., 25, 79-120 

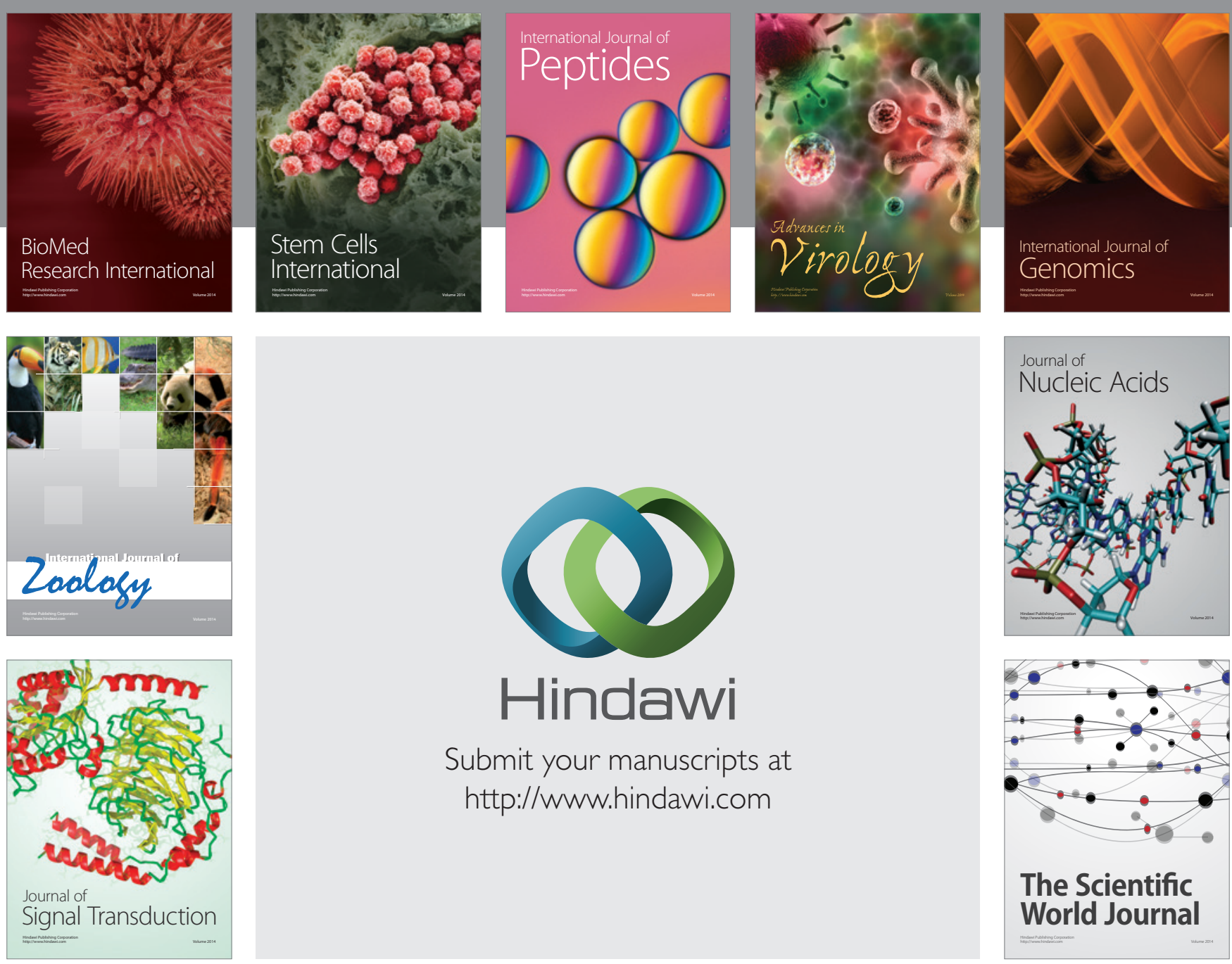

Submit your manuscripts at

http://www.hindawi.com
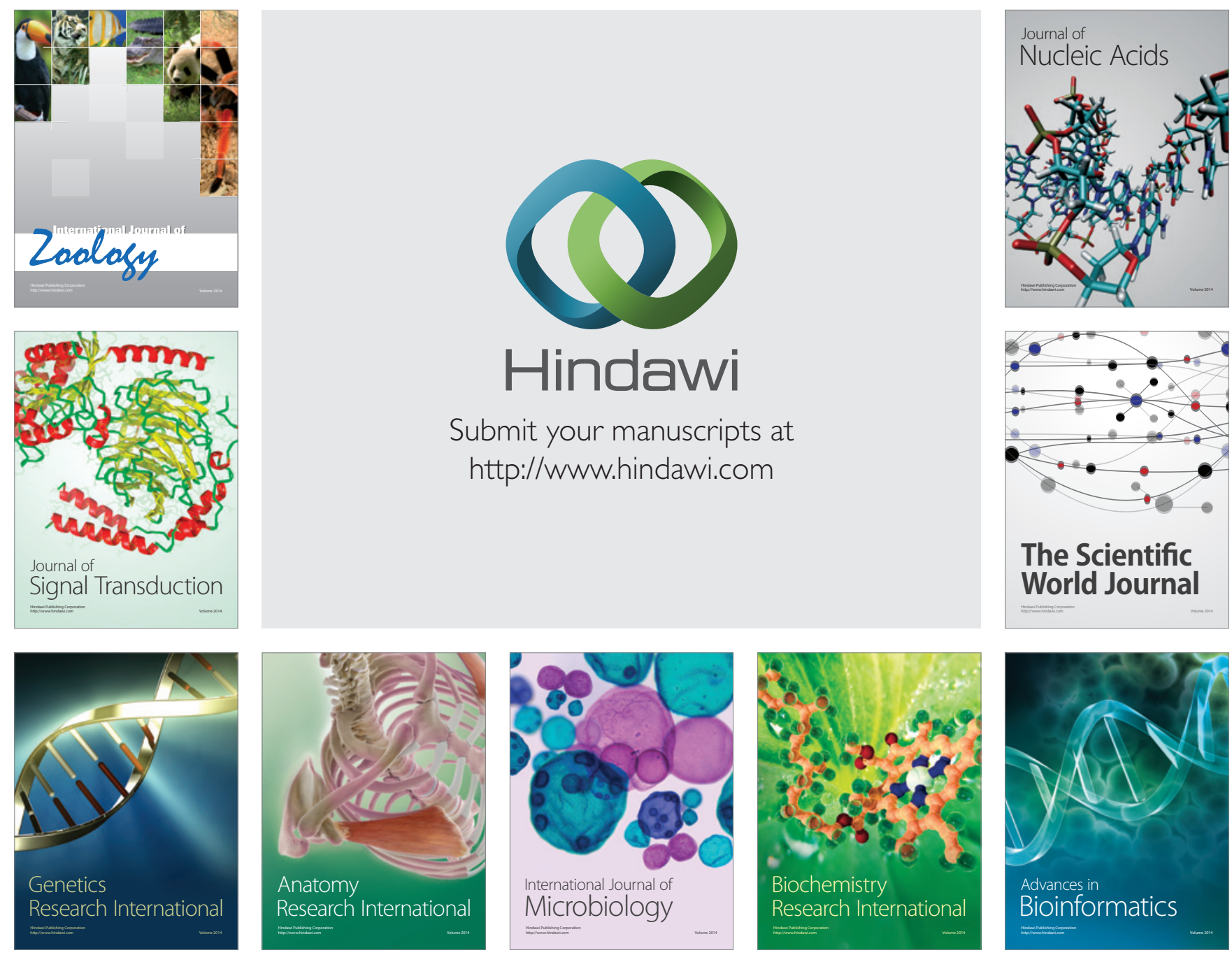

The Scientific World Journal
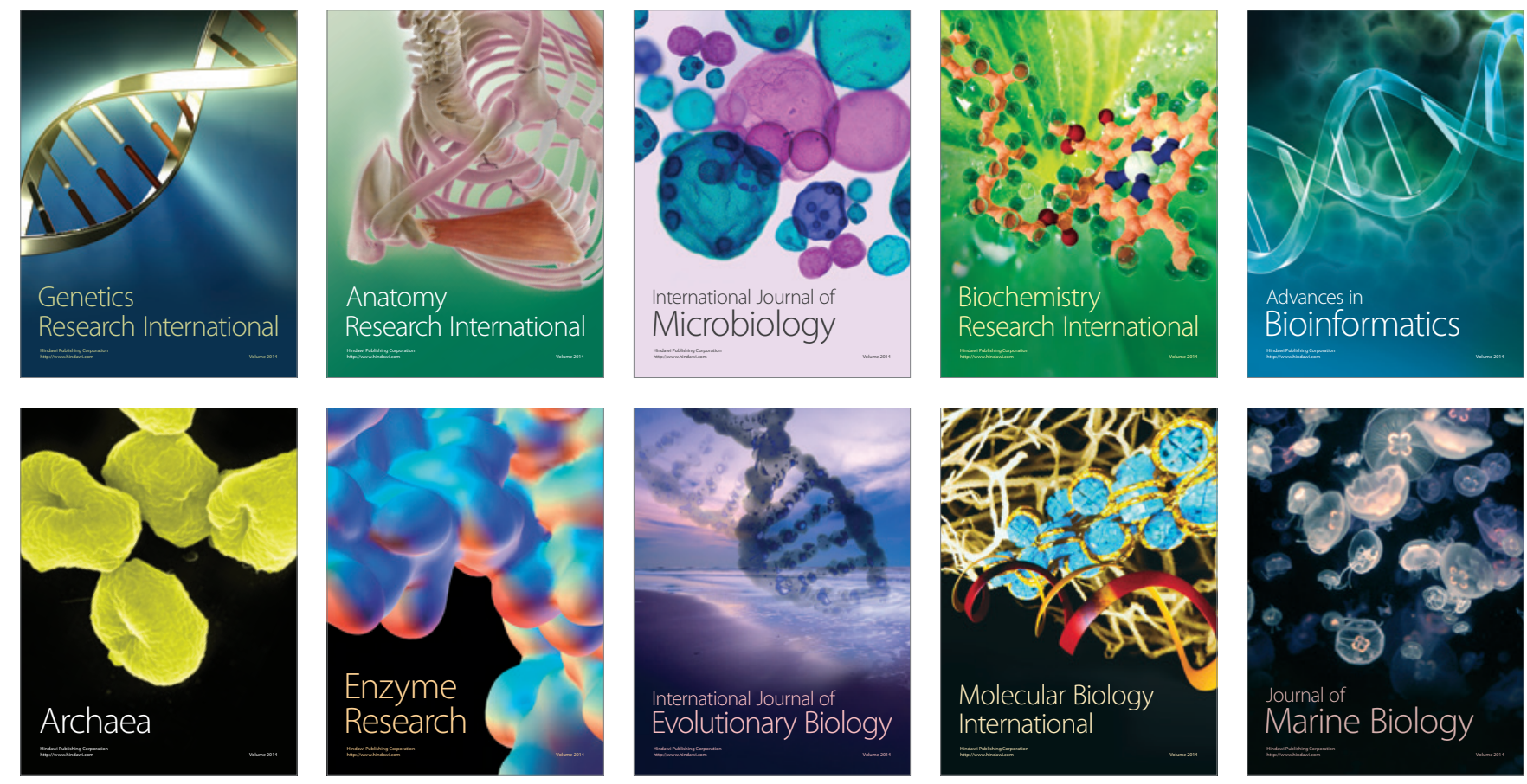